\title{
Associations between functional polymorphisms in antioxidant defense genes and urinary oxidative stress biomarkers in healthy, premenopausal women
}

\author{
Umaima Al-Alem • Peter H. Gann • Jeffrey Dahl • \\ Richard B. van Breemen - Vilas Mistry • Patricia M. W. Lam • \\ Mark D. Evans • Linda Van Horn • Margaret E. Wright
}

Received: 23 July 2011/Accepted: 17 October 2011/Published online: 9 November 2011

(C) Springer-Verlag 2011

\begin{abstract}
Functional polymorphisms in endogenous antioxidant defense genes including manganese superoxide dismutase (MnSOD), catalase (CAT), and glutathione peroxidase (GPX-1) have been linked with risk of cancer at multiple sites. Although it is presumed that these germline variants impact disease risk by altering the host's ability to detoxify mutagenic reactive oxygen species, very few studies have directly examined this hypothesis. Concentrations of 8 -isoprostane F2 $\alpha$ (8-iso-PGF $2 \alpha)$ and 8-oxo-7, 8 -dihydro-2'-deoxyguanosine (8-oxoxdG)-sensitive indicators of lipid peroxidation and DNA oxidation, respectively-were measured in 24-h urine samples obtained from 93 healthy, premenopausal women participating in a dietary intervention trial. In addition, DNA was extracted from blood for genotyping of MnSOD Val16Ala, CAT-262
\end{abstract}

\section{U. Al-Alem}

Division of Epidemiology and Biostatistics, University of Illinois at Chicago School of Public Health, 1603 W Taylor St., Chicago, IL, USA

P. H. Gann · M. E. Wright $(\square)$

Department of Pathology, University of Illinois at Chicago

College of Medicine, 840 S Wood St, CSN 130,

Chicago, IL 60612, USA

e-mail: mewright@uic.edu

\section{J. Dahl · R. B. van Breemen}

Department of Medicinal Chemistry and Pharmacognosy, University of Illinois at Chicago College of Pharmacy,

Chicago, IL, USA

V. Mistry · P. M. W. Lam · M. D. Evans

Department of Cancer Studies and Molecular Medicine,

University of Leicester, Leicester, UK

L. Van Horn

Department of Preventive Medicine, Northwestern University, Feinberg School of Medicine, Chicago, IL, USA
C > T, and GPX1 Pro198Leu genotypes by Taqman assay. Although geometric mean concentrations of 8 -iso-PGF2 ${ }_{\alpha}$ and 8-oxoxdG varied across several study characteristics including race, education level, body mass index, and serum antioxidant levels, there was little evidence that these biomarkers differed across any of the examined genotypes. In summary, functional polymorphisms in endogenous antioxidant defense genes do not appear to be strongly associated with systemic oxidative stress levels in young, healthy women.

Keywords Antioxidant - Biomarker - Oxidative stress · Polymorphism · Women

\section{Introduction}

Oxidative damage to DNA, lipids, and proteins due to excessive levels of reactive oxygen species (ROS) has been implicated in the pathogenesis of many diseases, including cancer (Roberts et al. 2009). Although antioxidants obtained through the diet afford some measure of protection against ROS, endogenous antioxidant enzymes provide the primary defense against intracellular oxidative stress (Yu 1994). Manganese superoxide dismutase (MnSOD), catalase (CAT), and glutathione peroxidase (GPX-1) are the primary endogenous antioxidant defense enzymes, and they work cooperatively to detoxify free radicals: MnSOD catalyzes the conversion of highly reactive superoxide radicals to hydrogen peroxide and CAT and GPX-1 detoxify hydrogen peroxide into water and oxygen (Yu 1994). The genes encoding these enzymes are polymorphic and three germline single nucleotide polymorphisms (SNPs)—MnSOD Val16Ala (rs4880), CAT-262 C > T (rs1001179), and GPX1 Pro198Leu 
(rs1050450)_lead to alterations in enzyme activity. While the CAT and GPX1 polymorphisms result in decreased enzyme activity (Bastaki et al. 2006), both higher (Sutton et al. 2006) and lower (Bastaki et al. 2006) activity has been associated with the MnSOD variant.

The MnSOD, CAT, and GPX1 variants have each been linked with risks of multiple cancers. Some of the most consistent associations have been observed for breast cancer, either directly or indirectly through interactions with dietary intakes of antioxidant nutrients/antioxidantrich foods or prooxidant lifestyle exposures (Ambrosone et al. 1999; Mitrunen and Hirvonen 2001; Cai et al. 2004; Ahn et al. 2005; Ravn-Haren et al. 2006). It is generally presumed that these polymorphisms influence cancer risk by altering the host's ability to neutralize toxic free radicals. While results from in vitro and knockout mouse model studies support this (Melov et al. 1999; Van Remmen et al. 2003, 2004), there are very few reports describing oxidative stress levels in relation to the aforementioned genetic variants in humans. We therefore evaluated whether urinary concentrations of 8 -isoprostane $\mathrm{F} 2 \alpha$ (8-iso-PGF $2 \alpha$ ) and 8-oxo-7,8-dihydro-2'-deoxyguanosine (8-oxoxdG)—sensitive indicators of global lipid peroxidation (Halliwell and Whiteman 2004) and DNA oxidation (Cooke et al. 2009), respectively - vary across the MnSOD Val16Ala, CAT-262 C > T, and GPX1 Pro198Leu genotypes in a population of young healthy women.

\section{Materials and methods}

The Diet and Hormone Study was a randomized trial designed to examine the effects of a low fat $(<20 \%$ of calories), high fruit and vegetable ( $>8$ servings per day), and high-fiber (25-30 g per day) diet on hormone levels in healthy premenopausal women (Gann et al. 2003). Two hundred and thirteen women between the ages of 20 and 40 years were randomly assigned to either the dietary intervention group or usual diet group for a total of 15 months. At 12 months, participants were re-randomized to a soy supplement with or without isoflavones in addition to their original dietary assignment. Written informed consent was obtained from each participant prior to randomization, and Institutional Review Board Approval for the present ancillary study was secured.

The present analysis is based on women randomized to the usual diet (control) group who provided demographic, lifestyle, dietary, and medical information, as well as fasting blood and a 24-h urine sample, at baseline (prior to randomization). At baseline, participants completed three 24-h diet recalls and a validated Block food frequency questionnaire (FFQ); the three recalls were averaged to estimate the mean dietary intake of macro- and micronutrients, while the FFQ was utilized to capture vitamin supplement use. Baseline fasting blood samples were processed immediately after collection; plasma, buffy coat, and red blood cells were separated, aliquoted, and stored at $-70^{\circ} \mathrm{C}$. Upon return of the $24-\mathrm{h}$ urine collection, the entire sample was mixed thoroughly, aliquoted, and stored at $-70^{\circ} \mathrm{C}$. Urinary concentrations of 8 -iso-PGF $2 \alpha$ and 8-oxoxdG were successfully measured in 87 and 93 of the 107 participants randomized to the usual diet group.

Genomic DNA was isolated from buffy coat samples and TaqMan $^{\circledR}$ assays (Applied Biosystems) were used to genotype the three polymorphisms of interest. There were no deviations from Hardy-Weinberg Equilibrium for any SNP. Repeat genotyping of $10 \%$ of samples showed $100 \%$ concordance.

8 -iso-PGF $2 \alpha$ was measured using a rapid liquid chromatography-tandem mass spectrometry (LC-MS/MS) assay (Dahl and van Breemen 2010). Urinary 8-oxoxdG levels were quantified using ultra-high performance LC-MS/MS (Lam et al. in preparation). In order to monitor the reproducibility of each assay, de-identified urine samples were obtained from the University of Illinois at Chicago Clinical Pathology lab and mixed together to create a quality control pool; multiple aliquots of this pool were analyzed with each batch of study samples. The average intra- and inter-batch coefficients of variation were 17 and $24 \%$ for 8 -iso-PGF $2 \alpha$ and 3 and $10 \%$ for 8-oxoxdG, respectively.

8 -iso-PGF $2 \alpha$ and 8-oxoxdG values were log-transformed and geometric mean concentrations and $95 \%$ confidence intervals across study characteristics and genotypes were determined using generalized linear models in SAS version 9.1.3 (SAS Institute, Cary, NC).

\section{Results}

Study participants were young, predominantly Caucasian, well educated, physically active and lean, and most did not currently smoke. Higher 8 -iso-PGF $2 \alpha$ concentrations were observed in African Americans, among women without a college degree, in those who were overweight or obese, and in participants in the lowest tertile of serum $\alpha$-carotene (Table 1) - a nutrient concentrated in fruits and vegetables that displays in vitro antioxidant activity. 8-oxoxdG exhibited similar patterns, and it was additionally noted that levels were highest in the least physically active women and among those who reported taking aspirin at any time during the past year. Neither of these biomarkers demonstrated significant variation across categories defined by antioxidant supplement use, levels of serum antioxidants other than $\alpha$-carotene, fruit and vegetable intake, nor intakes of individual antioxidant or prooxidant nutrients (data not shown). There were no significant trends in either biomarker across any of the antioxidant defense genotypes (Table 2). Although there 
was a suggestion of lower 8-iso-PGF $2_{\alpha}$ and higher 8-oxoxdG concentrations among women with the homozygous variant CAT genotype, these results should be interpreted with caution as very few participants carried two copies of the variant CAT allele.

\section{Discussion}

In this study, urinary biomarkers of oxidative stress did not exhibit significant variation across functional germline
SNPs in the primary endogenous antioxidants enzymes, MnSOD, CAT, and GPX-1. One potential explanation is that our study population consisted of young, healthy women with limited oxidative burden but who nonetheless are at an age when tumor development might begin. Alternatively, genotype-phenotype associations might only be apparent when the aforementioned SNPs are considered in combination, particularly since they act cooperatively in the body. Unfortunately, our sample size did not permit this type of analysis. Six studies have investigated whether oxidative stress levels vary as a function of antioxidant

Table 1 Unadjusted geometric mean concentrations of urinary biomarkers of oxidative stress according to study characteristics

\begin{tabular}{|c|c|c|c|c|c|c|}
\hline \multirow[t]{2}{*}{ Characteristics } & \multicolumn{3}{|c|}{$\begin{array}{l}8 \text {-isoprostane } \mathrm{F} 2{ }_{\alpha}(\mathrm{pg} / \mathrm{ml}) \\
n=87\end{array}$} & \multicolumn{3}{|c|}{$\begin{array}{l}\text { 8-oxo-7,8-dihydro-2'-deoxyguanosine (pmol/ml) } \\
n=93\end{array}$} \\
\hline & $n$ & Mean $(95 \% \mathrm{CI})$ & $P$-value ${ }^{\mathrm{a}}$ & $n$ & Mean $(95 \% \mathrm{CI})$ & $P$-value ${ }^{\mathrm{a}}$ \\
\hline \multicolumn{7}{|l|}{ Age (years) } \\
\hline$<30$ & 27 & $183(131,255)$ & 0.25 & 29 & $9.82(8.35,11.54)$ & 0.10 \\
\hline $30-34$ & 26 & $133(94,186)$ & & 28 & $8.21(6.96,9.68)$ & \\
\hline$\geq 35$ & 34 & $190(141,257)$ & & 37 & $10.36(8.98,11.96)$ & \\
\hline \multicolumn{7}{|l|}{$\operatorname{Race}^{\mathrm{b}}$} \\
\hline Caucasian & 68 & $157(128,193)$ & 0.04 & 71 & $9.28(8.35,10.32)$ & 0.71 \\
\hline African American & 9 & $286(163,501)$ & & 13 & $11.23(8.77,14.38)$ & \\
\hline Hispanic & 4 & $262(113,608)$ & & 4 & $9.55(6.11,14.92)$ & \\
\hline Asian & 5 & $88(41,187)$ & & 5 & $8.86(5.94,13.2)$ & \\
\hline \multicolumn{7}{|l|}{ Education } \\
\hline$<$ College degree & 13 & $254(157,410)$ & 0.07 & 15 & $11.56(9.23,14.48)$ & 0.06 \\
\hline$\geq$ College graduate & 74 & $157(128,192)$ & & 79 & $9.16(8.31,10.11)$ & \\
\hline \multicolumn{7}{|l|}{ Smoking status } \\
\hline Never & 60 & $162(129,204)$ & 0.43 & 65 & $9.96(8.93,11.11)$ & 0.24 \\
\hline Former & 23 & $169(117,244)$ & & 24 & $8.33(6.96,9.96)$ & \\
\hline Current & 4 & $294(122,706)$ & & 5 & $9.85(6.65,14.59)$ & \\
\hline \multicolumn{7}{|c|}{ Body mass index $\left(\mathrm{kg} / \mathrm{m}^{2}\right)$} \\
\hline$<25$ & 64 & $150(121,186)$ & 0.04 & 67 & $9.45(8.48,10.54)$ & 0.84 \\
\hline$\geq 25$ & 23 & $234(164,335)$ & & 27 & $9.65(8.13,11.45)$ & \\
\hline \multicolumn{7}{|l|}{ Physical activity ${ }^{\mathrm{c}}$} \\
\hline Light & 25 & $206(145,292)$ & 0.28 & 27 & $10.94(9.26,12.93)$ & 0.08 \\
\hline Moderate & 40 & $167(127,220)$ & & 43 & $9.39(8.22,10.72)$ & \\
\hline Heavy & 22 & $136(94,198)$ & & 24 & $8.31(6.96,9.92)$ & \\
\hline \multicolumn{7}{|l|}{ Aspirin use ${ }^{\mathrm{d}}$} \\
\hline No & 59 & $176(140,221)$ & 0.52 & 63 & $8.78(7.88,9.78)$ & 0.01 \\
\hline Yes & 28 & $154(111,215)$ & & 31 & $11.18(9.59,13.05)$ & \\
\hline \multicolumn{7}{|c|}{ Serum $\alpha$-carotene $(\mu \mathrm{g} / \mathrm{dl})$} \\
\hline$<5.1$ & 27 & $266(195,363)$ & 0.001 & 31 & $9.92(8.45,11.65)$ & 0.74 \\
\hline $5.1-8.35$ & 27 & $172(126,234)$ & & 30 & $9.08(7.71,10.69)$ & \\
\hline$>8.35$ & 30 & $115(86,154)$ & & 30 & $9.43(8.01,11.1)$ & \\
\hline
\end{tabular}

${ }^{a} P$-value from ANOVA $F$-test

b Excludes 1 individual classified as "other"

${ }^{c}$ Based on the validated CARDIA physical activity score (Sidney et al. 1991)

${ }^{\mathrm{d}}$ Ever use during the past 12 months 
Table 2 Geometric mean concentrations of urinary biomarkers of oxidative stress by endogenous antioxidant defense genotypes

\begin{tabular}{|c|c|c|c|c|c|c|c|c|c|c|}
\hline \multirow[t]{2}{*}{ Genotype } & \multicolumn{5}{|c|}{8 -isoprostane $\mathrm{F} 2_{\alpha}(\mathrm{pg} / \mathrm{ml})$} & \multicolumn{5}{|c|}{ 8-oxo-7,8-dihydro-2'-deoxyguanosine ( $\mathrm{pmol} / \mathrm{ml})$} \\
\hline & $N$ & $\begin{array}{l}\text { Unadjusted mean } \\
(95 \% \mathrm{CI})\end{array}$ & $p$-trend ${ }^{\mathrm{a}}$ & $\begin{array}{l}\text { Adjusted mean } \\
(95 \% \text { CI })\end{array}$ & $p$-trend ${ }^{\mathrm{a}}$ & $n$ & $\begin{array}{l}\text { Unadjusted mean } \\
(95 \% \text { CI })\end{array}$ & $p$-trend ${ }^{\mathrm{a}}$ & $\begin{array}{l}\text { Adjusted mean }{ }^{\mathrm{c}} \\
(95 \% \mathrm{CI})\end{array}$ & $p$-trend ${ }^{\mathrm{a}}$ \\
\hline \multicolumn{11}{|c|}{ SOD Val ${ }^{16} \mathrm{Ala}$} \\
\hline Val/Val & 26 & $156(107,229)$ & 0.55 & $159(103,244)$ & 0.49 & 28 & $9.47(7.83,11.47)$ & 0.42 & $10.02(8.03,12.49)$ & 0.75 \\
\hline Ala/Val & 40 & $200(152,263)$ & & $202(145,282)$ & & 43 & $9.72(8.48,11.15)$ & & $10.27(8.58,12.29)$ & \\
\hline Ala/Ala & 21 & $138(98,194)$ & & $190(128,284)$ & & 22 & $9.18(7.75,10.87)$ & & $9.38(7.58,11.61)$ & \\
\hline \multicolumn{11}{|c|}{ CAT $-262 \mathrm{C}>\mathrm{T}$} \\
\hline $\mathrm{CC}$ & 57 & $179(142,226)$ & 0.28 & $217(159,297)$ & 0.11 & 62 & $9.33(8.33,10.44)$ & 0.25 & $9.99(8.61,11.58)$ & 0.10 \\
\hline $\mathrm{TC}$ & 27 & $158(112,221)$ & & $167(117,239)$ & & 28 & $9.55(8.07,11.29)$ & & $10.36(8.49,12.63)$ & \\
\hline $\mathrm{TT}$ & 3 & $101(37,277)$ & & $70(28,172)$ & & 3 & $13.13(7.86,21.94)$ & & $15.39(9.07,26.12)$ & \\
\hline \multicolumn{11}{|c|}{ GPX Pro ${ }^{198}$ Leu } \\
\hline Pro/Pro & 45 & $152(117,197)$ & 0.62 & $166(120,229)$ & 0.58 & 46 & $9.71(8.53,11.04)$ & 0.65 & $10.23(8.49,12.34)$ & 0.69 \\
\hline Leu/Pro & 32 & $209(154,285)$ & & $240(164,351)$ & & 35 & $10.22(8.82,11.84)$ & & $10.75(8.86,13.05)$ & \\
\hline Leu/Leu & 10 & $136(78,236)$ & & $188(114,310)$ & & 10 & $6.92(5.26,9.13)$ & & $8.07(6.00,10.86)$ & \\
\hline
\end{tabular}

defense genotypes (Hong et al. 2002; Taufer et al. 2005; Lee et al. 2006; Park et al. 2006; Zhang et al. 2008; Karahalil et al. 2011), with three showing higher DNA damage levels among carriers of the MnSOD variant alanine (Hong et al. 2002; Taufer et al. 2005) or GPX-1 variant Leu (Lee et al. 2006) alleles. Notably, only one study was conducted in young, non-diseased individuals (Park et al. 2006), and the results from this study were concordant with our own.

A significant strength of our study is the use of two measures of oxidative stress that have demonstrated reproducibility, biological validation by virtue of consistent associations with disease states and known stressors such as smoking, and evidence of modulation by antioxidants and/or antioxidant-rich foods. For example, levels of 8-isoPGF $2 \alpha$ are elevated in active or passive smokers and can be reduced by vitamin $\mathrm{C}$ or increased fruit and vegetable intake in some studies (Reilly et al. 1996). With respect to 8-oxoxdG, studies have found its levels to be higher in smokers (Pilger et al. 2001) and in individuals with lower fruit and vegetable intake and serum vitamin $\mathrm{C}$ concentrations (Huang et al. 2000). Several small trials have also shown that administration of fruits and vegetables decreases 8-oxoxdG concentrations in healthy human volunteers (Halliwell 2002). Other strengths of our study include measurement of each analyte in urine rather than blood, which avoids potential artifactual oxidation (Patel et al. 2007); use of 24-h rather than spot urine samples, which are more robust to intra-individual variability in biomarkers (Pilger et al. 2001); and measurement of analytes by the sensitive mass spectrometry (rather than ELISA) approach (Evans et al. 2010). Finally, DHS participants were young and healthy, which minimized the effects of preclinical or overt disease on concentrations of oxidative stress biomarkers.

Limitations of our study include the relatively small number of subjects available for analysis and our reliance on previous reports showing that the three polymorphisms of interest are functional. Unfortunately, budgetary constraints precluded measurement of antioxidant enzyme activities in DHS subjects.

In summary, our findings do not support the hypothesis that polymorphisms in MnSOD, CAT, and GPX-1 are associated with systemic biomarkers of oxidative stress in young, healthy women. Future studies should examine the combined effects of all three genetic variants on oxidative stress levels, and whether these associations are modified by antioxidative or prooxidative lifestyle exposures.

Acknowledgments Funding was provided by a pilot grant from the University of Illinois at Chicago Cancer Center.

Conflict of interest None.

\section{References}

Ahn J, Gammon MD, Santella RM, Gaudet MM, Britton JA, Teitelbaum SL, Terry MB, Nowell S, Davis W, Garza C, Neugut AI, Ambrosone CB (2005) Associations between breast cancer risk and the catalase genotype, fruit and vegetable consumption, and supplement use. Am J Epidemiol 162:943-952 
Ambrosone CB, Freudenheim JL, Thompson PA, Bowman E, Vena JE, Marshall JR, Graham S, Laughlin R, Nemoto T, Shields PG (1999) Manganese superoxide dismutase (MnSOD) genetic polymorphisms, dietary antioxidants, and risk of breast cancer. Cancer Res 59:602-606

Bastaki M, Huen K, Manzanillo P, Chande N, Chen C, Balmes JR, Tager IB, Holland N (2006) Genotype-activity relationship for Mn-superoxide dismutase, glutathione peroxidase 1 and catalase in humans. Pharmacogenet Genomics 16:279-286

Cai Q, Shu XO, Wen W, Cheng JR, Dai Q, Gao YT, Zheng W (2004) Genetic polymorphism in the manganese superoxide dismutase gene, antioxidant intake, and breast cancer risk: results from the Shanghai Breast Cancer Study. Breast Cancer Res 6:R647-R655

Cooke MS, Henderson PT, Evans MD (2009) Sources of extracellular, oxidatively-modified DNA lesions: implications for their measurement in urine. J Clin Biochem Nutr 45:255-270

Dahl JH, van Breemen RB (2010) Rapid quantitative analysis of 8-iso-prostaglandin-F(2alpha) using liquid chromatography-tandem mass spectrometry and comparison with an enzyme immunoassay method. Anal Biochem 404:211-216

Evans MD, Olinski R, Loft S, Cooke MS, European Standards Committee on Urinary (DNA) Lesion Analysis (2010) Toward consensus in the analysis of urinary 8-oxo-7, 8-dihydro-2'deoxyguanosine as a noninvasive biomarker of oxidative stress. FASEB J 24:1249-1260

Gann PH, Chatterton RT, Gapstur SM, Liu K, Garside D, Giovanazzi S, Thedford K, Van Horn L (2003) The effects of a low-fat/highfiber diet on sex hormone levels and menstrual cycling in premenopausal women: a 12-month randomized trial (the diet and hormone study). Cancer 98:1870-1879

Halliwell B (2002) Effect of diet on cancer development: is oxidative DNA damage a biomarker? Free Radic Biol Med 32:968-974

Halliwell B, Whiteman M (2004) Measuring reactive species and oxidative damage in vivo and in cell culture: how should you do it and what do the results mean? Br J Pharmacol 142:231-255

Hong YC, Lee KH, Yi CH, Ha EH, Christiani DC (2002) Genetic susceptibility of term pregnant women to oxidative damage. Toxicol Lett 129:255-262

Huang H, Helzlsouer KJ, Appel LJ (2000) The effects of vitamin C and vitamin $\mathrm{E}$ on oxidative DNA damage: results from a randomized controlled trial. Cancer Epidemiol Biomarkers Prev 9:647-652

Karahalil B, Kesimci E, Emerce E, Gumus T, Kanbak O (2011) The impact of OGG1, MTH1 and MnSOD gene polymorphisms on 8-hydroxy-2'-deoxyguanosine and cellular superoxide dismutase activity in myocardial ischemia-reperfusion. Mol Biol Rep 38:2427-2435

Lee CH, Lee KY, Choe KH, Hong YC, Noh SI, Eom SY, Ko YJ, Zhang YW, Yim DH, Kang JW, Kim H, Kim YD (2006) Effects of oxidative DNA damage and genetic polymorphism of the glutathione peroxidase 1 (GPX1) and 8-oxoguanine glycosylase 1 (hOGG1) on lung cancer. J Prev Med Public Health 39:130-134

Melov S, Coskun P, Patel M, Tuinstra R, Cottrell B, Jun AS, Zastawny TH, Dizdaroglu M, Goodman SI, Huang TT, Miziorko H, Epstein CJ, Wallace DC (1999) Mitochondrial disease in superoxide dismutase 2 mutant mice. Proc Natl Acad Sci USA 96:846-851
Mitrunen K, Hirvonen A (2001) Association between manganese superoxide dismutase (MnSOD) gene polymorphism and breast cancer risk. Carcinogenesis 22:827-829

Park SY, Lee KH, Kang D, Lee KH, Ha EH, Hong YC (2006) Effect of genetic polymorphisms of MnSOD and MPO on the relationship between PAH exposure and oxidative DNA damage. Mutat Res 593:108-115

Patel VB, Spencer CH, Young TA, Lively MO, Cunningham CC (2007) Effects of 4-hydroxynonenal on mitochondrial 3-hydroxy-3-methylglutaryl (HMG-CoA) synthase. Free Radic Biol Med 43:1499-1507

Pilger A, Germadnik D, Riedel K, Meger-Kossien I, Scherer G, Rudiger HW (2001) Longitudinal study of urinary 8-hydroxy-2' deoxyguanosine excretion in healthy adults. Free Radic Res 35:273-280

Ravn-Haren G, Olsen A, Tjonneland A, Dragsted LO, Nexo BA, Wallin H, Overvad K, Raaschou-Nielsen O, Vogel U (2006) Associations between GPX1 Pro198Leu polymorphism, erythrocyte GPX activity, alcohol consumption and breast cancer risk in a prospective cohort study. Carcinogenesis 27:820-825

Reilly M, Delanty N, Lawson JA, Fitzgerald GA (1996) Modulation of oxidant stress in vivo in chronic cigarette smokers. Circulation 94:19-25

Roberts RA, Laskin DL, Smith CV, Robertson FM, Allen EM, Doorn JA, Slikker W (2009) Nitrative and oxidative stress in toxicology and disease. Toxicol Sci 112:4-16

Sidney S, Jacobs DR Jr, Haskell WL, Armstrong MA, Dimicco A, Oberman A, Savage PJ, Slattery ML, Sternfeld B, Van Horn L (1991) Comparison of two methods of assessing physical activity in the Coronary Artery Risk Development in Young Adults (CARDIA) Study. Am J Epidemiol 133:1231-1245

Sutton A, Nahon P, Pessayre D, Rufat P, Poire A, Ziol M, Vidaud D, Barget N, Ganne-Carrie N, Charnaux N, Trinchet JC, Gattegno L, Beaugrand M (2006) Genetic polymorphisms in antioxidant enzymes modulate hepatic iron accumulation and hepatocellular carcinoma development in patients with alcohol-induced cirrhosis. Cancer Res 66:2844-2852

Taufer M, Peres A, de Andrade VM, de Oliveira G, Sa G, do Canto ME, dos Santos AR, Bauer ME, da Cruz IB (2005) Is the Val16Ala manganese superoxide dismutase polymorphism associated with the aging process? J Gerontol A Biol Sci Med Sci 60:432-438

Van Remmen H, Ikeno Y, Hamilton M, Pahlavani M, Wolf N, Thorpe SR, Alderson NL, Baynes JW, Epstein CJ, Huang TT, Nelson J, Strong R, Richardson A (2003) Life-long reduction in MnSOD activity results in increased DNA damage and higher incidence of cancer but does not accelerate aging. Physiol Genomics 16:29-37

Van Remmen H, Qi W, Sabia M, Freeman G, Estlack L, Yang H, Mao Guo Z, Huang TT, Strong R, Lee S, Epstein CJ, Richardson A (2004) Multiple deficiencies in antioxidant enzymes in mice result in a compound increase in sensitivity to oxidative stress. Free Radic Biol Med 36:1625-1634

Yu BP (1994) Cellular defenses against damage from reactive oxygen species. Physiol Rev 74:139-162

Zhang J, Masciocchi M, Lewis D, Sun W, Liu A, Wang Y (2008) Placental anti-oxidant gene polymorphisms, enzyme activity, and oxidative stress in preeclampsia. Placenta 29:439-443 